\title{
Retention of the Immunological Proteins of Pasteurized Human Milk in Relation to Pasteurizer Design and Practice
}

\author{
CHARLES CZANK, DANIELLE K. PRIME, BEN HARTMANN, KAREN SIMMER, AND PETER E. HARTMANN
}

Discipline of Biochemistry and Molecular Biology [C.C., D.K.P., P.E.H.], The University of Western Australia, Crawley, Western Australia, 6009, Australia; Perron Rotary Express Milk Bank [B.H.], King Edward Memorial Hospital, Subiaco, Western Australia, 6008, Australia; School of Women's and Infants' Health [K.S.], The University of Western Australia, Crawley, Western Australia, 6009,

Australia

\begin{abstract}
Pasteurizing donor human milk inactivates bacteria that may be of concern to the preterm infant. However, current practice for Holder Pasteurization $\left(62.5^{\circ} \mathrm{C}\right.$ for $\left.30 \mathrm{~min}\right)$ is detrimental to the bioactivity of human milk. An experimental pasteurizer was used to determine the maximum temperature at which $90 \%$ of secretory $\operatorname{Ig} \mathrm{A}$, lysozyme, and lactoferrin were retained and whether this temperature was capable of inactivating five common bacterial contaminants. The retention of these proteins was also compared using a commercially available bottle immersion or holding chamber system. After pasteurization at $62.5^{\circ} \mathrm{C}$ for $30 \mathrm{~min}$, the retention across all three systems was $72.3 \pm 3.6 \%, 21.8 \pm 3.3 \%$, and $39.4 \pm$ $11.5 \%$ for $\operatorname{sIgA}$, lactoferrin, and lysozyme, respectively $(n=22)$. The retention of all three proteins was at least $90 \%$ when human milk was pasteurized at $57^{\circ} \mathrm{C}$ for $30 \mathrm{~min}$, and this temperature was also effective at removing $99.9 \%$ of all inoculated bacterial species. In addition, human milk that was pasteurized in the experimental system had a significantly higher proportion of lysozyme compared with samples pasteurized in the bottle immersion system. These findings suggest that optimizing pasteurization temperature and improving pasteurizer design enhances the quality of pasteurized donor human milk. (Pediatr Res 66: 374-379, 2009)
\end{abstract}

$\mathrm{P}$ asteurized donor human milk (PDHM) is considered to be the best alternative to mother's own milk (MOM) for feeding preterm infants, because it contains additional protective and developmental factors not found in infant formula (1). During the expression and collection of human milk, microbial contamination can occur and therefore DHM is pasteurized to prevent transfer of pathogens to the infant.

Current pasteurization methods use simple heating protocols to decrease the level of bacterial contamination to noninfectious levels. Current Australian guidelines (2), as well as the Human Milk Banking Association of North America (HMBANA) and the United Kingdom Association for Milk Banking (UKAMB; 3,4), recommend that human milk should be pasteurized using the Holder Pasteurization method, whereby the monitored temperature of the human milk should not fall below $62.5^{\circ} \mathrm{C}$ for $30 \mathrm{~min}$. It is also recommended that

Received March 17, 2009; accepted June 5, 2009.

Correspondence: Charles Czank, B.Sc. (Hons), Discipline of Biochemistry and Molecular Biology, School of Biomedical, Biomolecular and Chemical Sciences, The University of Western Australia, 35 Stirling Hwy, Crawley, Western Australia, 6009, Australia; e-mail: chuck@tartarus.uwa.edu.au

Supported by the Rotary Clubs of Thornlie and Belmont (Western Australia), The Women and Infants Research Foundation, The Perron Charitable Trust, and Medela AG (Switzerland) human milk containing a microbial load greater than $1 \times 10^{5}$ colony-forming units $/ \mathrm{mL}(\mathrm{CFU} / \mathrm{mL})$, bacterial species capable of producing heat-stable enterotoxins, or any pathogens should be rejected (2-4). It is likely that, historically, these recommended pasteurization regimes were adopted from the dairy industry where these conditions were required to inactivate the most heat-resistant, nonspore-forming human pathogens, Mycobacterium tuberculosis and Coxiella burnetti (5). The major purpose of pasteurization in the dairy industry is to prevent the transfer of such pathogens to the consumer and increase shelf life (6), whereas less concern is given to the nutritional changes to the milk that may occur during pasteurization. These pasteurization conditions may not be ideal for human milk, where the retention of bioactivity is highly desirable for sick and preterm babies.

Inevitably, the mechanism of thermal inactivation of bacteria during pasteurization also results in considerable loss of beneficial proteins present in human milk. This can be attributed to the "broad action" of heat that disrupts cell membranes and proteins through thermally induced denaturation (7). Typically, Holder Pasteurization can reduce the function of the immunoprotective proteins, such as secretory immunoglobulin A (sIgA), lactoferrin, and lysozyme, as much as $80 \%(8-10)$. Although clinical data suggests that PDHM is as protective in the prevention of necrotizing enterocolitis in the preterm infant as MOM (11), these studies demonstrate the need for a re-evaluation of human milk pasteurization conditions in the context of maximizing the retention of bioactive components.

Human milk pasteurizer design is an additional issue that must be considered. Most human milk pasteurizers submerge bottles of DHM in a heated water bath for the required time, followed by immersion in a chilled water bath until the milk has returned to the desired temperature. Although such systems are able to process a large volume of human milk, the length of time required to heat the milk to the desired temperature (lag time) is often either equivalent to or just short of the holding time. Furthermore, the lack of mixing of the human milk during pasteurization can often result in fat separation and clumping, making it difficult to resuspend in

\footnotetext{
Abbreviations: CFU/ml, colony-forming units/milliliter; DHM, donor human milk; MOM, mother's own milk; PDHM, pasteurized donor human milk; sIgA, secretory immunoglobulin A
} 
the milk. Both of these issues can be potentially resolved using a semiflow-through system that heats the milk quickly and also mixes it. This study compared the effectiveness of these two different designs in relation to the retention of immunologic proteins (sIgA, lactoferrin, and lysozyme) of human milk. A third experimental pasteurizer was used to determine the optimal pasteurization conditions for protein retention and the effectiveness of these conditions on inactivating common bacterial contaminants found in DHM.

\section{METHODS}

Samples. Samples of human milk used for studying the effects of pasteurization were obtained from the Perron Rotary Expressed Milk Bank (PREM Bank), King Edward Memorial Hospital, Subiaco, Western Australia. All donors gave written consent for their donations to be used in research, and this study was approved by The University of Western Australia ethics review board.

Holder Pasteurization. Human milk samples were pasteurized using the Holder Method $\left(62.5^{\circ} \mathrm{C}\right.$ for $\left.30 \mathrm{~min}\right)$ in three different systems. The T30 (Sterifeed, UK) is a bottle immersion-type pasteurizer, wherein 11 bottles containing $250 \mathrm{~mL}$ of DHM are submerged in a heated water bath for the required time and then cooled by transferring the bottles to a chilled water bath. The Human Milk Pasteurizer (Saurin Industries, Australia) pumps 750 $\mathrm{mL}$ of DHM through a heating coil and into a holding chamber, where it is held for the required time and temperature. The milk is then pumped through a cooling coil and collected for dispensing. Because the temperature resolution of the bottle immersion and holding chamber pasteurizers was $\pm 1.5^{\circ} \mathrm{C}$ and $\pm 0.5^{\circ} \mathrm{C}$, respectively, the actual pasteurizer temperature was adjusted, so that a minimum holding temperature of $62.5^{\circ} \mathrm{C}$ was maintained.

For the purpose of optimizing pasteurization conditions, an experimental pasteurizer was designed specifically for this study (Carag AG, Switzerland). The experimental pasteurization system was simplistic and used a precision water bath (Huber AG, Germany) capable of maintaining temperatures $\pm 0.1^{\circ} \mathrm{C}$ of the desired temperatures. Human milk was pasteurized by injecting $50 \mathrm{~mL}$ of chilled human milk into a $3-\mathrm{mm}$ diameter stainless steel coil attached to the lid of the water bath. The coil was then submerged into the precisely heated water bath. The temperature of the milk was monitored indirectly using a pair of type $\mathrm{K}$ thermocouples (sampling rate of $1 \mathrm{~Hz}$ ) mounted $1.5 \mathrm{~mm}$ apart in a separate $3-\mathrm{mm}$ diameter stainless steel coil filled with water to simulate the thermal characteristics of human milk. Both these coils were attached to the lid of the water bath, so that they could be submerged simultaneously into the water bath for the desired period of time (Fig. 1). The thermocouples were mounted in this way, so that simultaneous measurements of the inside surface of the stainless steel coil and the temperature at the center of the diameter coil could be recorded. After the desired pasteurization time, the coil containing the milk was transferred to insulated container connected to a cooling system. After the temperature of the milk reached $10^{\circ} \mathrm{C}$, the milk was decanted from the coil, and samples were taken

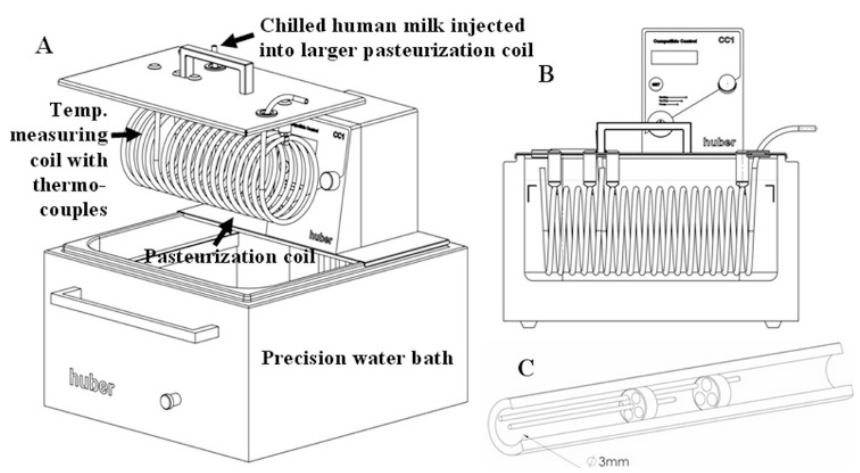

Figure 1. Technical details of experimental pasteurization system. A, Exploded view of pasteurization system illustrating human milk pasteurization coil, temperature measuring coil, and precision water bath; $B$, Front view of experimental system demonstrating the position of the coils when submerged in precision water bath; $C$, Cross-sectional view of a section of the temperature measurement coil exemplifying the position of the thermocouples for monitoring temperature during pasteurization. for further analysis. Temperature data were acquired via a data acquisition system (Delta Ohm, Italy) connected to a personal computer, and subsequent analysis was performed using DeltaLog9 version 2.4 software (Delta Ohm).

Measurement of protein retention. The $\operatorname{sgA}$ and lactoferrin content of human milk samples were quantified by the sandwich ELISA method as previously described (12). All antibodies and standards were purchased from MP Biomedicals Australasia (New South Wales, Australia). Lysozyme content of human milk samples was quantified using a Human Lysozyme enzyme immunoassay (EIA) kit (Biomedical Technologies, Inc., MA) according to manufacturer's instructions.

Bacteriology. Five bacterial species were chosen for this study on consultation with the microbiology laboratory that routinely screens samples of human milk donated to the PREM Bank. Lyophilized preparations of Staphylococcus aureus (ATCC 6538), Enterobacter cloacae (ATCC 27508), Bacillus cereus (ATCC 10702), and Staphylococcus epidermidis (ATCC 12228) were obtained from the American Type Culture Collection, VA. An overnight culture of Escherichia coli strain K12 (ATCC 14948) was obtained from Southern Biologic, New South Wales, Australia. E. coli and S. epidermidis were cultured as suspensions in nutrient broth, plated on nutrient agar, and incubated at $37^{\circ}$ C. E. cloacae and B. cereus were cultured as suspensions in nutrient broth, plated on nutrient agar (Southern Biological), and incubated at $30^{\circ} \mathrm{C}$. S. aureus was cultured as a suspension in Tryptic Soy Broth (BD Biosciences, CA) and plated on Tryptic Soy Agar (BD Biosciences, CA) at $37^{\circ} \mathrm{C}$. Bacterium suspension cultures were enumerated using the OD method (13) measured with a spectrophotometer (Biotek Pty Ltd, VT) at $600 \mathrm{~nm}$. For pasteurization, triplicate $50 \mathrm{~mL}$ samples of either the human milk or the appropriate nutrient media were inoculated with bacterial suspension to achieve a minimum concentration of $1 \times 10^{5} \mathrm{CFU} / \mathrm{mL}$ and pasteurized as described above using the experimental pasteurizer. To determine the decimal reduction time ( $D$ value) of each bacterial species inoculated into the human milk or nutrient media during pasteurization, samples were taken at $0,2.5,5$, $7.5,10,15,20,30$, and $40 \mathrm{~min}$, aliquots $(5-100 \mu \mathrm{L})$ plated on the appropriate nutrient agar, and $\mathrm{CFU} / \mathrm{mL}$ enumerated $24 \mathrm{~h}$ later after incubation under the above conditions.

Statistical analysis. All averaged data are presented as mean $\pm \mathrm{SD}$ ANOVA with Tukey-Kramer post hoc test (GraphPad InStat V3.0; GraphPad Software, Inc.) was used to compare mean values of groups of samples to determine the presence of a significant difference $(p<0.05)$. Graphical modeling of protein retention levels and rates of bacterial inactivation during pasteurization were performed using SigmaPlot 11.0 (Systat Software, Inc., CA).

\section{RESULTS}

Effect of heating time during Holder Pasteurization on the retention of human milk immunologic proteins. Although there was variation in the concentrations of the individual proteins measured before pasteurization, the proportion of each protein retained after pasteurization was relatively consistent across all three pasteurization systems (Table 1). Secretory $\operatorname{IgA}$ had the greatest level of retention ranging between 68.5 and $72.9 \%(n=22)$. Lysozyme was the next greatest retained protein between 32.8 and $52.5 \%(n=22)$, and lactoferrin was the least retained protein in the range of 18.3 to $24.8 \%$ (Table $1 ; n=22$ ). There was no significant difference between the proportion of $\operatorname{sIgA}$ and lactoferrin that was retained as a result of pasteurizing using the different systems. However, significantly greater lysozyme was retained $(p<$ 0.01 ) in the human milk that was pasteurized using the experimental pasteurizer $(n=6)$ compared with the bottle immersion pasteurizer $(n=10)$.

Considerable variation in lag time occurred between the three pasteurization systems, with the bottle immersion system requiring $30 \mathrm{~min}$ and the holding chamber system requiring $15 \mathrm{~min}$ to heat the milk to the $62.5^{\circ} \mathrm{C}$. Comparatively, the experimental pasteurization system allowed for rapid heating of the milk in an average of $45.3 \pm 2.6 \mathrm{~s}(n=$ 6) with excellent maintenance of holding temperature, producing an ideal heating profile (Fig. $2 A$ ). On closer inspec- 
Table 1. Comparison of the retention of immunological human milk proteins during Holder Pasteurisation (62.5 ${ }^{\circ} \mathrm{C}$ for 30 min) using 3 different pasteurization systems

\begin{tabular}{|c|c|c|c|c|c|c|c|c|c|c|}
\hline & \multicolumn{9}{|c|}{ Pasteurization system (manufacturer) } & \multirow[b]{3}{*}{$\begin{array}{c}\text { Overall average } \\
\% \text { retain }\end{array}$} \\
\hline & \multicolumn{3}{|c|}{ Bottle emersion (Sterifeed) } & \multicolumn{3}{|c|}{ Holding chamber (Saurin Industries) } & \multicolumn{3}{|c|}{ Experimental (Carag AG) } & \\
\hline & $\begin{array}{l}\text { Before } \\
\text { g/L }\end{array}$ & After $\mathrm{g} / \mathrm{L}$ & $\%$ Retain & Before $\mathrm{g} / \mathrm{L}$ & After $\mathrm{g} / \mathrm{L}$ & $\%$ Retain & $\begin{array}{l}\text { Before } \\
\text { g/L }\end{array}$ & $\begin{array}{l}\text { After } \\
\text { g/L }\end{array}$ & $\%$ Retain & \\
\hline sIgA g/L (SD) & $2.3(0.5)$ & $1.6(0.4)$ & $72.9(8.3)$ & $1.5(0.8)$ & $1.1(0.6)$ & $75.6(6.3)$ & $0.9(0.3)$ & $0.6(0.2)$ & $68.5(7.1)$ & $72.3(3.6)$ \\
\hline Lactoferrin g/L (SD) & $1.33(0.7)$ & $0.25(0.15)$ & $22.4(14.7)$ & $0.78(0.09)$ & $0.10(0.06)$ & $18.3(6.5)$ & $1.0(0.5)$ & $0.3(0.3)$ & $24.8(12.0)$ & $21.8(3.3)$ \\
\hline Lysozyme mg/L (SD) & $173(80)$ & $80(14)$ & $30.8 *(12.5)$ & $63(6.0)$ & $20(2)$ & $35.0(13.2)$ & $127(12)$ & $62(11)$ & $52.5^{*}(9.8)$ & $39.4(11.5)$ \\
\hline$n$ & & 10 & & & 6 & & & 6 & & \\
\hline
\end{tabular}

$* p<0.01$.
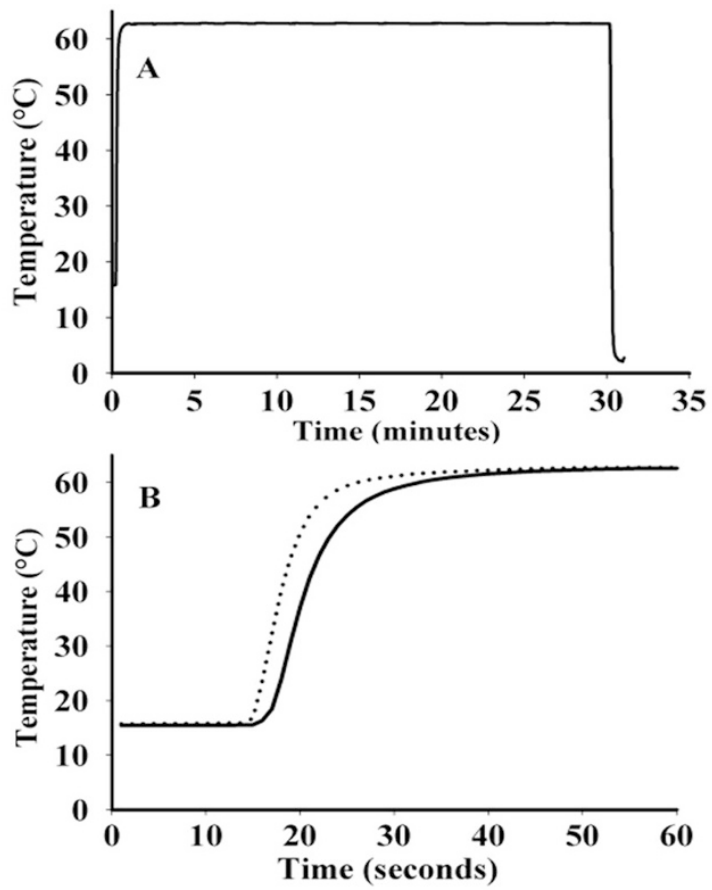

Figure 2. Heating profile of human milk pasteurized at $62.5^{\circ} \mathrm{C}$ for $30 \mathrm{~min}$ with an experimental pasteurizer. $A$, Complete heating profile during the pasteurization cycle; $B$, The first $60 \mathrm{~s}$ of the pasteurization cycle illustrating the difference in heating rates of the center (solid line) and the inside surface of the stainless steel coil (broken line).

tion, however, it is apparent that the majority of the lag time was associated with increasing the temperature of the milk from 59.5 to $62.5^{\circ} \mathrm{C}$ (Fig. $2 B$ ). There was also a considerable difference in heating rates at the center and the inside surface of the coil, suggesting that a temperature gradient was generated across the 3-mm diameter of the stainless steel coil in which the human milk was pasteurized (Fig. 2B).

Optimal Holder Pasteurization temperature for maximizing the retention of immunologic proteins. By using the precision temperature control of the experimental pasteurization system, it was possible to accurately quantify the retention of each protein in relation to time at specific pasteurization temperatures in $1^{\circ} \mathrm{C}$ increments (Fig. 3). The change in protein retention over time was quantified by calculating the rate of individual protein loss from the mean retention values of each protein $(n=6)$. Under currently accepted Holder Pasteurization conditions $\left(62.5^{\circ} \mathrm{C}\right.$ for $\left.30 \mathrm{~min}\right)$, protein loss was $1.6 \%$ reduction of protein per min for $\operatorname{sIgA}, 1.7 \%$ per min for lysozyme, and $2.4 \%$ per min for lactoferrin. Reducing the temperature to $60^{\circ} \mathrm{C}$ decreased the rate of protein loss for $\operatorname{sig} \mathrm{A}$ and lactoferrin $(0.9 \% / \mathrm{min}$ and $1.9 \% / \mathrm{min}$, respectively), but it was less pronounced for lysozyme $(1.6 \% / \mathrm{min})$. At $59^{\circ} \mathrm{C}$, protein loss rates were slightly less for $\operatorname{sIgA}$ at $0.6 \% / \mathrm{min}$ and lactoferrin at $1.7 \% / \mathrm{min}$, whereas lysozyme loss fell to $1.4 \%$ / min. Further lowering of the pasteurization temperature to $58^{\circ} \mathrm{C}$ resulted in a protein loss rate for lactoferrin $(1.4 \% / \mathrm{min})$, with a decrease in protein loss for $\operatorname{sIgA}(0.5 \% / \mathrm{min})$ and lysozyme $(1.3 \% / \mathrm{min})$. For all three proteins measured, the highest rate of protein retention occurred at $57^{\circ} \mathrm{C}(0.2 \% / \mathrm{min}$ for $\operatorname{sIg} \mathrm{A}, 0.4 \% / \mathrm{min}$ for lactoferrin, and $0.2 \% / \mathrm{min}$ for lysozyme). At this temperature, the rate of protein retention was either similar or identical to what occurred at $40^{\circ} \mathrm{C}(0.2 \% / \mathrm{min}$ for all three proteins). This decreased rate of protein loss resulted in the retention of all three proteins at levels greater than $90 \%$ at all time points measured.
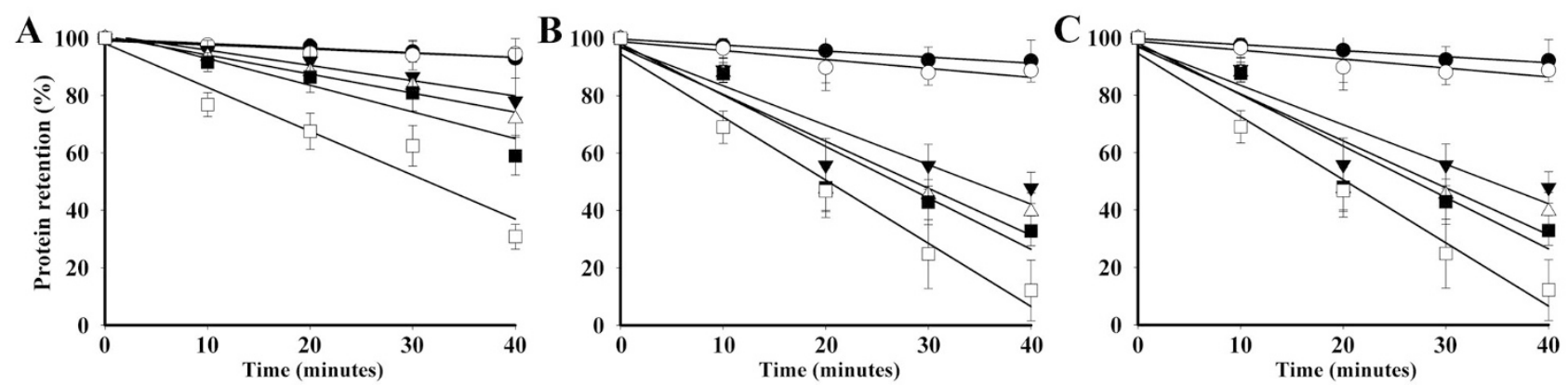

Figure 3. Rates of $\operatorname{sIgA}(A)$, lysozyme $(B)$, and lactoferrin $(C)$ loss in human milk pasteurized either at or below $62.5^{\circ} \mathrm{C}(\square)$. Greater than $90 \%$ of all three proteins were retained at $57^{\circ} \mathrm{C}(\bigcirc)$. The other temperatures evaluated were $58^{\circ} \mathrm{C}(\nabla), 59^{\circ} \mathrm{C}(\triangle), 60^{\circ} \mathrm{C}(\square)$, and $40^{\circ} \mathrm{C}(\bullet)$. Data points are the mean $\pm \mathrm{SD}, n=6$. 

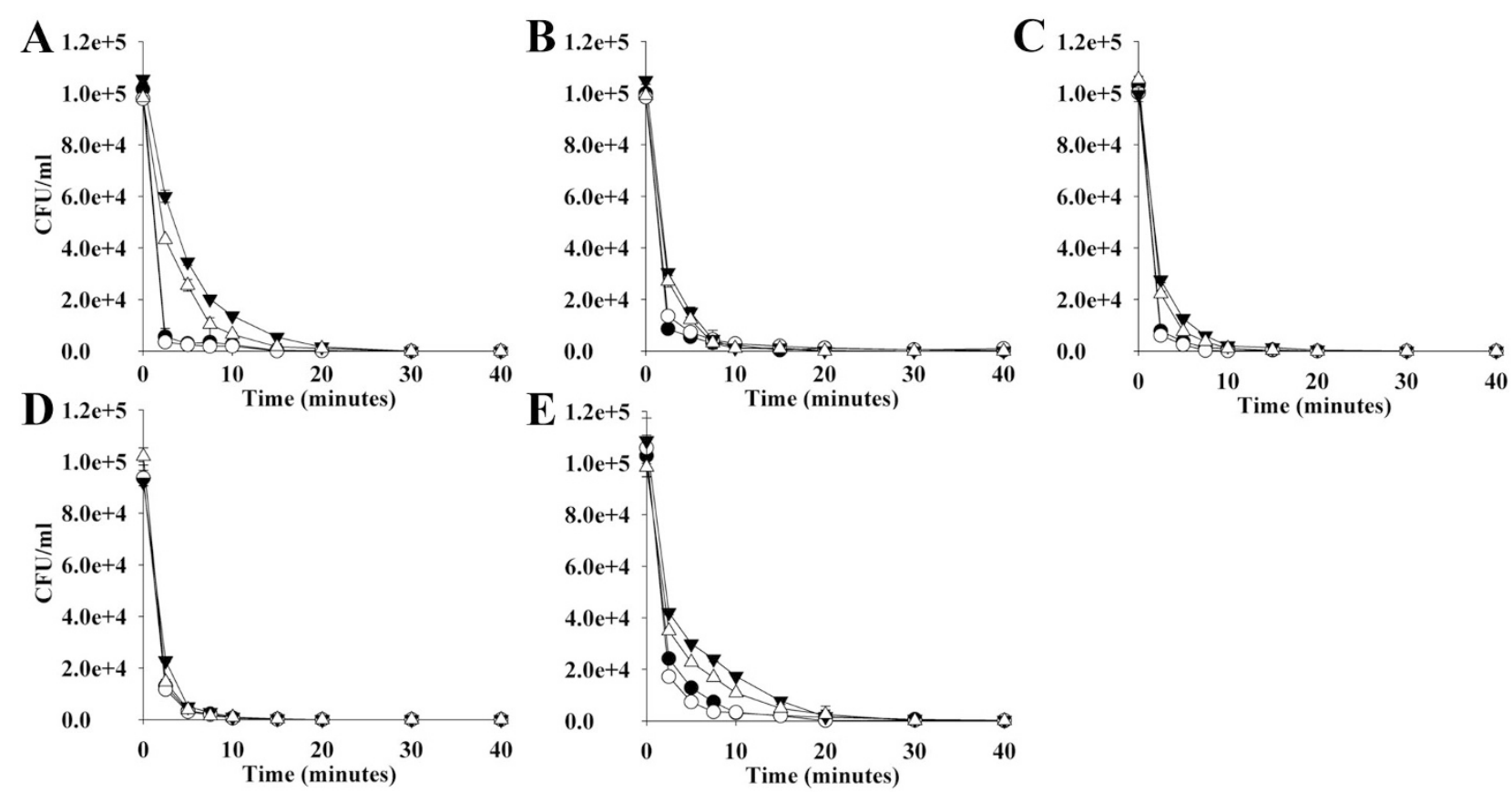

Figure 4. Thermal death profiles of bacteria during pasteurization. E. coli $(A)$, S. epidermidis $(B)$, E. cloacae $(C)$, B. cereus $(D)$, and $S$. aureus $(E)$ inoculated into human milk and pasteurized at $57^{\circ} \mathrm{C}(\boldsymbol{\nabla})$, inoculated into nutrient media and pasteurized at $57^{\circ} \mathrm{C}(\triangle)$, inoculated into human milk and pasteurized at $62.5^{\circ} \mathrm{C}$ (๑), inoculated into nutrient media and pasteurized at $62.5^{\circ} \mathrm{C}(\bigcirc)$. Data points are the mean $\pm \mathrm{SD}, n=3$.

Effect of reducing pasteurization temperature on the inactivation kinetics of common bacterial contaminants found in DHM. For all bacterial species tested, thermal treatment at $62.5^{\circ} \mathrm{C}$ resulted in a greater rate of reduction in viable cell number than at $57^{\circ} \mathrm{C}$. Pasteurization at $62.5^{\circ} \mathrm{C}$ for 20 min reduced the numbers of all bacterial species by at least $99.9 \%$, whereas $30 \mathrm{~min}$ at $57^{\circ} \mathrm{C}$ was needed to achieve the same results (Fig. 4). Susceptibility to the pasteurization treatment was found to be dependent on the pasteurization temperature (Table 2). As determined from the decimal reduction values $(D), S$. aureus exhibited the greatest heat resistance, followed by B. cereus and Enterobacter cloacae, whereas E. coli and S. epidermidis were the least heat resistant at the higher temperature. Reducing the pasteurization temperature appeared to alter the thermal resistance of the bacterial species, with E. coli demonstrating the

Table 2. Thermal susceptibility (as determined by decimal reduction time [D]) of bacterium species subjected to 62.5 and $57^{\circ} \mathrm{C}$ in either $\mathrm{DHM}$ or nutrient media

\begin{tabular}{llcr}
\hline & & \multicolumn{2}{c}{$D$ (min) } \\
\cline { 2 - 3 } Bacterial species & \multicolumn{1}{c}{ Medium } & $62.5^{\circ} \mathrm{C}$ & $57^{\circ} \mathrm{C}$ \\
\hline E. coli & DHM & 5.4 & 16.4 \\
S. epidermidis & Nutrient medium & 3.9 & 14.8 \\
& DHM & 5.6 & 10.5 \\
E. cloacae & Nutrient medium & 5.4 & 9.7 \\
& DHM & 7.1 & 10.7 \\
B. cereus & Nutrient medium & 5.5 & 8.1 \\
S. aureus & DHM & 7.8 & 9.2 \\
& Nutrient medium & 7.4 & 8.4 \\
& DHM & 11.9 & 15.3 \\
& Nutrient medium & 11.6 & 13.4 \\
\hline
\end{tabular}

greatest heat resistance, whereas S. aureus, E. cloacae, $S$. epidermidis, and B. cereus displayed similar thermal resistance at this temperature.

In all cases, the rate of cell number reduction was less in DHM compared with the nutrient medium. This was more evident at $57^{\circ} \mathrm{C}$ than at $62.5^{\circ} \mathrm{C}$, although there was little difference observed for S. epidermidis, B cereus, and S. aureus at the higher temperature.

\section{DISCUSSION}

The three antimicrobial proteins measured in the current study constitute approximately a third of the total protein in human milk and make an important contribution to the antibacterial activity of the milk (14). Despite the large range (e.g. sIgA ranged $0.9-2.3 \mathrm{~g} / \mathrm{L}$ ) in protein content of human milk samples pasteurized in the different systems, protein retention was similar across all three pasteurization systems (Table 1). Furthermore, the proportion of $\operatorname{sIg}$ A and lactoferrin retained after pasteurization was similar to previous studies $(15,16)$.

The optimal temperature (of those tested) for the greatest retention of immunologic proteins in human milk was $57^{\circ} \mathrm{C}$. This finding was notably similar to the studies of Wills et al. and Lawrence, which established that pasteurization at $56^{\circ} \mathrm{C}$ for 15 to $30 \mathrm{~min}$ retained higher proportions of immunologic proteins $(9,10)$. It is of interest that the Wills et al. study used an activity assay for determining lysozyme retention, whereas the current study relied on an ELISA method for quantifying this outcome. The latter method is used to quantify individual protein content based 
on tertiary structure (17), which may account for the considerably lower lysozyme retention observed in this study.

Our findings suggest that temperature, and not the holding time, is critical for the retention of these three proteins. For example, a temperature increase of just $1.7 \%$ (from $57^{\circ} \mathrm{C}$ to $58^{\circ} \mathrm{C}$ ) decreased retention of $\operatorname{sigA}$, lactoferrin, and lysozyme by $8.5,34$, and $31 \%$, respectively (Fig. 3). In comparison, a similar proportional change in holding time resulted in a $0.68,0.95$, and $0.89 \%$ decrease in the retention of sIgA, lactoferrin, and lysozyme, respectively. This illustrates that the importance of accurately monitoring and maintaining pasteurization temperature, because even a small change in temperature can have large adverse effects on the quality of PDHM. It follows that the precision of temperature monitoring will have important implications for milk banks in meeting quality control guidelines for pasteurization conditions, while at the same time retaining protein bioactivity.

Having established that $90 \%$ or more of the immunologic proteins were retained at $57^{\circ} \mathrm{C}$, it was necessary to determine whether this temperature was also suitable for inactivating a range of common bacteria found in DHM. Although previous studies have assessed the inactivation kinetics of E. coli, S. aureus, and group $\beta$-hemolytic Streptococci in human milk during Holder Pasteurization $\left(62.5^{\circ} \mathrm{C}\right.$ for $\left.30 \mathrm{~min} ; 18\right)$, this is the first study that examined B. cereus, $S$. epidermidis, and E. cloacae at this temperature and all five bacterial species at $57^{\circ} \mathrm{C}$. In the food industry, it is well established that the type of food, especially liquid food, can contribute to the effectiveness of pasteurization (19). Therefore, when determining the safety of a pasteurization process for a particular food, it is a common practice that the food of interest is inoculated with a known amount of bacteria and the effectiveness of pasteurization compared against a control. This study used a similar approach, whereby either the human milk or a control medium was inoculated with a final concentration of $10^{5} \mathrm{CFU} / \mathrm{mL}$ of an individual species of bacteria, equivalent to the maximum advisable allowable amount in DHM (2-4). In addition, low levels of bacteria were present in some milk samples before inoculation, as evidenced by the higher CFU counts than the number originally inoculated. Pasteurization at either $62.5^{\circ} \mathrm{C}$ for $20 \mathrm{~min}$ or $57^{\circ} \mathrm{C}$ for 30 min was sufficient to reduce all bacterial species tested by 99.9\% (Fig.4). The transfer of M. tuberculosis to the premature infant via DHM remains an important issue in human milk banking, although this risk has never been quantified. Dairy studies have demonstrated that pasteurizing at $62.5^{\circ} \mathrm{C}$ for $30 \mathrm{~min}$ readily inactivates this pathogen, whereas 90 to $95 \%$ are inactivated at $57^{\circ} \mathrm{C}$ for $30 \mathrm{~min}(20)$. Therefore, a conflict of interest exists between ensuring the inactivation of rare heat-resistant pathogens and retaining the components that benefit the preterm infant. Thus, current practice $\left(62.5^{\circ} \mathrm{C}\right.$ for $\left.30 \mathrm{~min}\right)$ may be considered as excessive for pasteurizing the majority of human milk donated to the human milk bank.

The heating profile during pasteurization was also examined in this study, a factor that is highly dependent on pasteurizer design. Compared with the bottle immersion system, the rapid heating (lag time) and cooling of the human milk could be achieved with the experimental system. This ideal heating profile may have contributed to the significant improvement in lysozyme retention, relative to the bottle immersion system. The effect of lag time on protein retention may also be important for Flash Pasteurization $\left(72^{\circ} \mathrm{C}\right.$ for $\left.15 \mathrm{~s}\right)$. It would be expected from our findings that longer lag times in heating milk from $57^{\circ} \mathrm{C}$ to $72^{\circ} \mathrm{C}$ would result in greater protein damage. In addition to the effect on protein retention, lag time is likely to affect the inactivation rates of bacteria. When compared with our findings, previous studies that used the bottle emersion method have demonstrated considerably shorter inactivation times of the bacteria tested in this study (18). This is likely due to the prolonged lag time associated with this method, contributing to bacterial inactivation. In contrast, the extremely short lag time of the experimental pasteurizer is likely to have less of an effect in this regard. Therefore, although a prolonged lag time contributes to bacterial inactivation, it also affects the quality of the final product, and the balance of these desired outcomes must be considered in the design of future human milk pasteurizers.

An advantage of the semiflow-through design of the holding chamber system was the enhanced mixing of the human milk that prevented fat clumping, a problem that is common to both the other pasteurizer designs. Clearly, this is an issue that deserves more attention and could potentially be resolved through future innovations in pasteurizer design and practice. Pasteurizer design is not only important for batch turnaround time but also critical to quality of the final product. As evidenced in this study, improving human milk pasteurization practice through milder conditions, accurate and precise monitoring of pasteurization temperature, and enhancing pasteurizer design to reduce lag time are an achievable means for increasing the quality of PDHM. However, further studies are required to assess the efficacy of pasteurization at $57^{\circ} \mathrm{C}$ on a wider range of microbial contaminants, including viruses.

Acknowledgments. The authors are grateful for the assistance of Mr. Lukas Christen and Mr. Beat Widmer (Carag AG, Switzerland) for providing the technical diagrams of the experimental pasteurizer and to the generosity of the human milk donors that made this research possible.

\section{REFERENCES}

1. Wight NE 2001 Donor human milk for preterm infants. J Perinatol 21:249-254

2. Hartmann BT, Pang WW, Keil AD, Hartmann PE, Simmer K 2007 Best practice guidelines for the operation of a donor human milk bank in an Australian NICU. Early Hum Dev 83:667-673

3. Human Milk Banking Association of North America 1995 Guidelines for the establishment and operation of a donor human milk bank. HMBANA, West Hartford, CT, pp 1-28

4. Balmer SE, Wiliams AF 1995 Guidelines for the establishment and operation of human milk banks in the UK. Arch Dis Child 73:481-482

5. Enright JB, Sadler WW, Thomas RC 1957 Thermal inactivation of Coxiella burnetii and its relation to pasteurization of milk. Public Health Monogr 47:1-30

6. Bylund G 2003 Dairy processing handbook. Tetra Pak Processing Systems AB, Lund, Sweden, pp 451-453 
7. Smelt JP, Hellemons JC, Wouters PC, van Gerwen SJ 2002 Physiological and mathematical aspects in setting criteria for decontamination of foods by physical means. Int J Food Microbiol 78:57-77

8. Björkstén B, Burman LG, De Château P, Fredrikzon B, Gothefors L, Hernell O 1980 Collecting and banking human milk: to heat or not to heat? BMJ 281: 765-769

9. Wills ME, Han VE, Harris DA, Baum JD 1982 Short-time low-temperature pasteurisation of human milk. Early Hum Dev 7:71-80

10. Lawrence RA 2001 Milk banking: the influence of storage procedures and subsequent processing on immunologic components of human milk. Adv Nutr Res 10:389-404

11. Lucas A, Cole TJ 1990 Breast milk and neonatal necrotizing enterocolitis. Lancet 336:1519-1523

12. Prentice A, Ewing G, Roberts SB, Lucas A, MacCarthy A, Jarjou LM, Whitehead RG 1987 The nutritional role of breast-milk IgA and lactoferrin. Acta Paediatr Scand 76:592-598
13. Monod J 1949 The growth of bacterial cultures. Annu Rev Microbiol 3:371-394

14. Lonnerdal B 2003 Nutritional and physiologic significance of human milk proteins. Am J Clin Nutr 77:1537S-1543S

15. Ford JE, Law BA, Marshall VM, Reiter B 1977 Influence of the heat treatment of human milk on some of its protective constituents. J Pediatr 90:29-35

16. Hamprecht K, Maschmann J, Müller D, Dietz K, Besenthal I, Goelz R, Middeldorp JM, Speer CP, Jahn G 2004 Cytomegalovirus (CMV) inactivation in breast milk: reassessment of pasteurization and freeze-thawing. Pediatr Res 56:529-535

17. Lequin RM 2005 Enzyme immunoassay (EIA)/enzyme-linked immunosorbent assay (ELISA). Clin Chem 51:2415-2418

18. Jones CL, Jennison RF, D'Souza SW 1979 Bacterial contamination of expressed breast milk. BMJ 2:1320-1322

19. David JR, Graves RH 1996 Aseptic Processing and Packaging of Food: A Food Industry Perspective. CRC Press, Boca Raton, pp 3-2

20. Ball CO 1943 Short-time pasteurization of milk. Ind Eng Chem 35:71-84 